\title{
Emf Measurements in the Liquid Au-Cu-Sn Lead-free Solder Alloys
}

\author{
A. Wierzbicka-Miernik, G. Garzel, and L.A. Zabdyr
}

(Submitted July 24, 2009; in revised form September 8, 2009)

\begin{abstract}
An emf method was employed to determine tin activities in the liquid Au-Cu-Sn alloys using solid electrolyte galvanic cells. The whole concentration range of the Gibbs triangle was covered, and emf readings were taken for both heating and cooling mode within temperature interval: 900-1360 K. Emf versus $T$ relations were approximated by line equations, and its coefficients were listed in tables. Tin activity versus composition curves were constructed, displaying negative deviation from ideal behavior. Activity data were compared to the respective values calculated from COST 531 database using binary formalism, and relatively good agreement was observed.
\end{abstract}

Keywords emf method, lead-free solders, thermodynamic properties

\section{Introduction}

$\mathrm{Au}-\mathrm{Cu}-\mathrm{Sn}$ alloys are considered as potential material for so called high-temperature (above $250^{\circ} \mathrm{C}$ ) lead-free solder applications. Some of them are already in use, like highgold content (20 wt.\% Sn) eutectic alloys. The main disadvantage of this material is its high cost, therefore, it would be advisable to lower gold content in solder material. On the other hand, tin-rich $\mathrm{Au}-\mathrm{Cu}-\mathrm{Sn}$ alloys are known to be extremely brittle because of the presence of $\mathrm{Au}-\mathrm{Sn}$ intermetallic phases, and especially $\mathrm{AuSn}_{4}$. To find out the optimal alloy composition, it is necessary to know phase equilibria in the $\mathrm{Sn}$-rich corner of $\mathrm{Au}-\mathrm{Cu}-\mathrm{Sn}$ ternary system, and the information on thermodynamic properties of liquid alloys under consideration is essential for this purpose.

Thermodynamic properties of liquid $\mathrm{Au}-\mathrm{Cu}-\mathrm{Sn}$ alloys were studied only once, so far by Knott et al. ${ }^{[1]}$ using calorimetric method, and this work is intended to complement thermodynamic description of this alloy system.

\section{Experimental}

Electromotive force measurement method was employed using solid-electrolyte galvanic cells according to scheme given below:

$$
\begin{aligned}
& \text { (-)Kanthal, } \mathrm{Re} \mid \mathrm{Au}-\mathrm{Cu}-\mathrm{Sn}_{(1)}, \mathrm{SnO}_{2(\mathrm{~s})}\left\|\mathrm{ZrO}_{2}-\mathrm{Y}_{2} \mathrm{O}_{3}\right\| \\
& \mathrm{Ni}_{(\mathrm{s})}, \mathrm{NiO}_{(\mathrm{s})} \mid \operatorname{Pt}(+)
\end{aligned}
$$

A. Wierzbicka-Miernik, G. Garzel, and L.A. Zabdyr, Institute of Metallurgy and Materials Science, Polish Academy of Sciences, 25 Reymonta St., 30-059 Krakow, Poland. Contact e-mail: nmzabdyr@ imim-pan.krakow.pl.
Detailed description of theoretical basis of measurement and of experimental equipment used were reported previously. ${ }^{[2]}$

Emf readings were taken within the temperature range: 900-1360 K for both heating and cooling mode. Alloy compositions were chosen to cover the whole range: for three cross sections of constant $\mathrm{Au}: \mathrm{Cu}$ ratio equal to: 3,1 , and $1 / 3$; all investigated compositions are shown on the Gibbs triangle of Fig. 1.

Because of different materials of current lead used: kanthal and platinum, correction for thermoelectric power was determined experimentally: $E_{\mathrm{p}}=-0.236363-5.45794 \times$ $10^{-4} T+8.31592 \times 10^{-6} T^{2}[\mathrm{mV}]$ and then added to measured emf values. Kanthal-rhenium joint was small enough to fit to the constant temperature zone, so there was no need to apply the additional correction.

\section{Results}

Linear dependence of emf on temperature was observed for all alloy compositions that were investigated; an example of an emf versus $T$ plot is shown for $\mathrm{Au}: \mathrm{Cu}=1$ cross section in Fig. 2.

Measurement results were approximated by straight line equations, and the respective line coefficients are listed in Table 1.

Tin activities were calculated from emf results and are listed in Table 1 using relations already described ${ }^{[2]}$ at an arbitrarily chosen temperature $1273 \mathrm{~K}$; they were then compared to the respective values calculated from COST 531 database $^{[3]}$ using binary formalism, as can be seen in Fig. 3-5.

Although cross sections of the earlier calorimetric measurements ${ }^{[1]}$ were not compatible with those in our study, ten common points were found with approximately the same composition, enabling comparison of results. Values of integral enthalpy of mixing measured calorimetrically were compared to the respective quantities, calculated from our emf data in Table 2; average relative error is $4.5 \%$. 


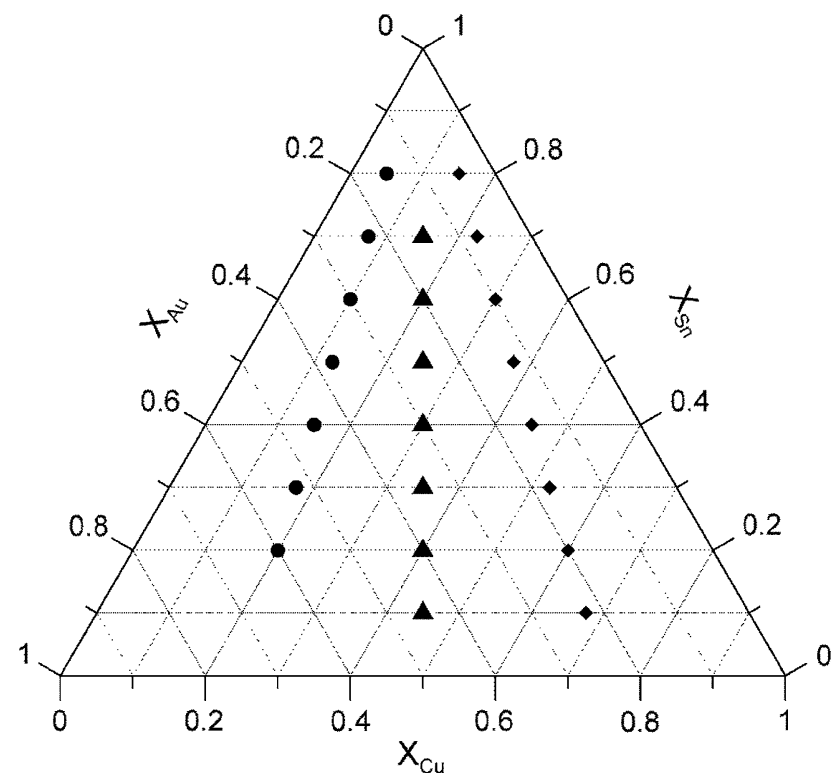

Fig. 1 Gibbs triangle with alloy compositions investigated

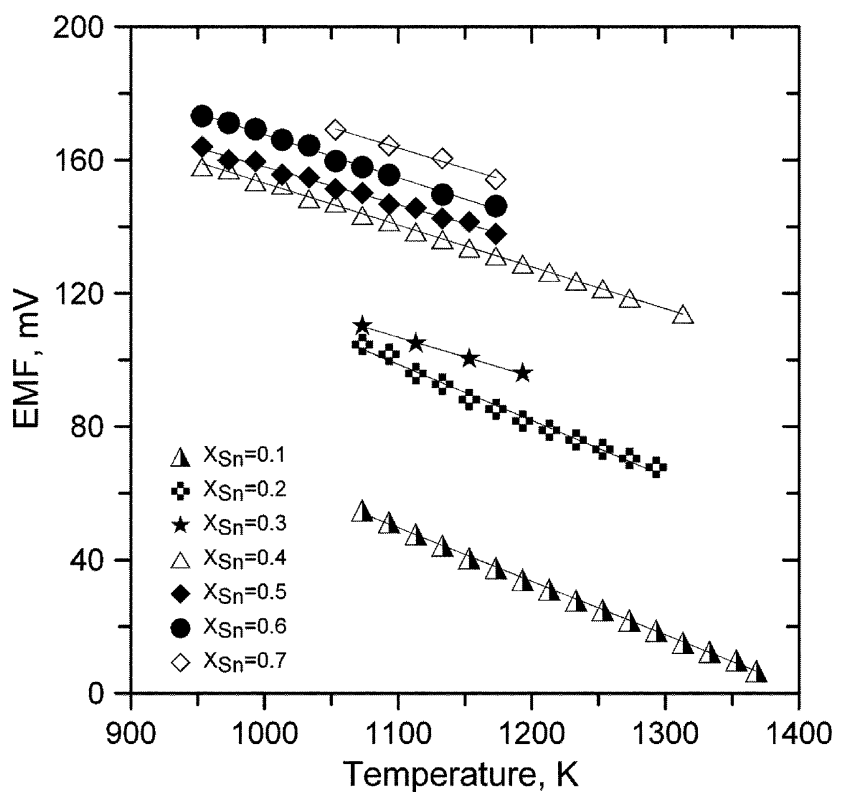

Fig. 2 Emf vs. $T$ plot for $\mathrm{Au}: \mathrm{Cu}=1$ cross section

Table 1 Coefficients of emf vs. $T$ lines for cross sections $\mathrm{Au}: \mathrm{Cu}=3$, 1 , and 1/3

\begin{tabular}{|c|c|c|c|c|c|c|}
\hline \multicolumn{7}{|c|}{$E=a( \pm \Delta a)+b( \pm \Delta b) T, \mathbf{m V}$} \\
\hline \multirow[b]{2}{*}{$X_{\text {Sn }}$} & \multicolumn{2}{|c|}{$X_{\mathrm{Au}}: X_{\mathrm{Cu}}=3: 1$} & \multicolumn{2}{|c|}{$X_{\mathrm{Au}}: X_{\mathrm{Cu}}=1: 1$} & \multicolumn{2}{|c|}{$X_{\mathrm{Au}}: X_{\mathrm{Cu}}=1: 3$} \\
\hline & $a( \pm \Delta a)$ & $b( \pm \Delta b)$ & $a( \pm \Delta a)$ & $b( \pm \Delta b)$ & $a( \pm \Delta a)$ & $b( \pm \Delta b)$ \\
\hline 0.1 & $\ldots$ & $\ldots$ & $226.30( \pm 1.60)$ & $-0.1605( \pm 0.0013)$ & $207.81( \pm 4.18)$ & $-0.1368( \pm 0.0035)$ \\
\hline 0.2 & $227.92( \pm 4.02)$ & $-0.1419( \pm 0.0033)$ & $283.63( \pm 6.25)$ & $-0.1681( \pm 0.0053)$ & $213.91( \pm 5.22)$ & $-0.1045( \pm 0.0045)$ \\
\hline 0.3 & $249.14( \pm 3.86)$ & $-0.1318( \pm 0.0033)$ & $237.63( \pm 3.87)$ & $-0.1189( \pm 0.0034)$ & $185.86( \pm 5.14)$ & $-0.0631( \pm 0.0044)$ \\
\hline 0.4 & $236.67( \pm 1.48)$ & $-0.1018( \pm 0.0012)$ & $270.86( \pm 2.69)$ & $-0.1189( \pm 0.0024)$ & $285.92( \pm 2.04)$ & $-0.12713( \pm 0.0018)$ \\
\hline 0.5 & $256.12( \pm 1.56)$ & $-0.1037( \pm 0.0013)$ & $270.83( \pm 2.02)$ & $-0.1130( \pm 0.002)$ & $287.60( \pm 4.14)$ & $-0.1207( \pm 0.0038)$ \\
\hline 0.6 & $290.12( \pm 2.62)$ & $-0.1222( \pm 0.0022)$ & $288.42( \pm 4.21)$ & $-0.1214( \pm 0.0041)$ & $298.06( \pm 4.30)$ & $-0.1246( \pm 0.0037)$ \\
\hline 0.7 & $257.67( \pm 1.62)$ & $-0.0896( \pm 0.0013)$ & $297.99( \pm 9.43)$ & $-0.1221( \pm 0.0085)$ & $288.34( \pm 2.41)$ & $-0.1120( \pm 0.0022)$ \\
\hline 0.8 & $233.55( \pm 2.28)$ & $-0.0662( \pm 0.0023)$ & $\cdots$ & $\cdots$ & $286.72( \pm 3.60)$ & $-0.1062( \pm 0.0034)$ \\
\hline
\end{tabular}

\section{Conclusions}

Tin activities in the liquid Au-Cu-Sn alloys were determined using emf method in the whole concentration range, for the first time. Linear dependence of emf on temperature was observed in all 22 different compositions.

Considerable negative deviation from ideal behavior was observed on activity versus composition curves and agreement with COST 531 data was relatively good.
Agreement of integral enthalpy values calculated from our emf data with those measured calorimetrically ${ }^{[1]}$ is very good, taking into account uncertainties in composition estimates as well as the accuracy of enthalpy calculations from emf data.

Results of our emf measurements will be used along with the calorimetric data to derive a full thermodynamic description of $\mathrm{Au}-\mathrm{Cu}-\mathrm{Sn}$ alloy system by CALPHAD method. 


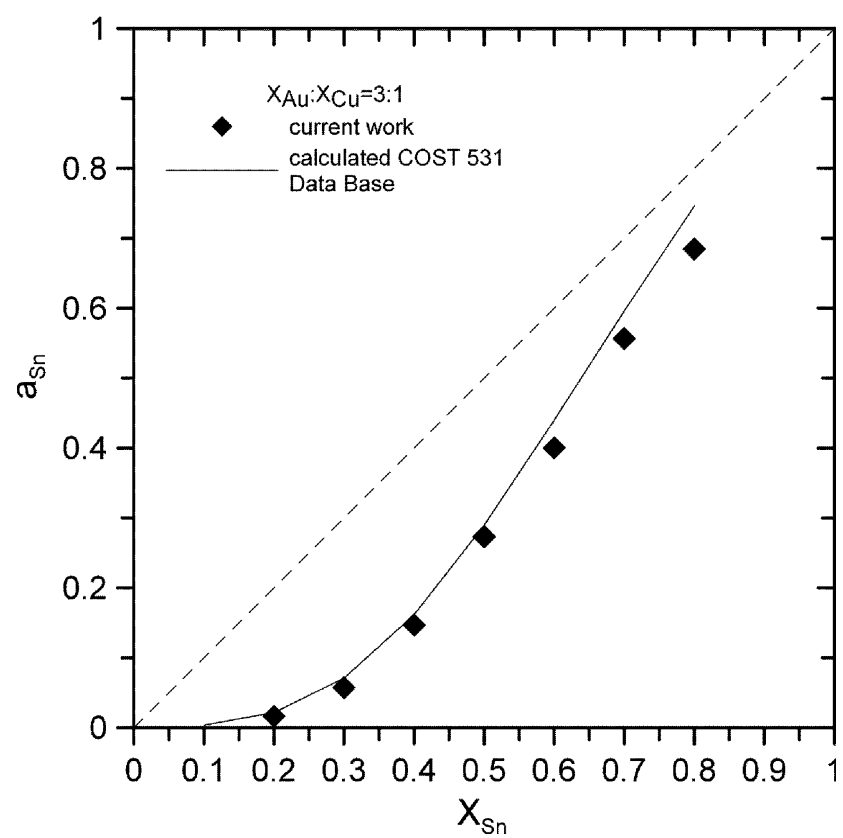

Fig. 3 Tin activity vs. composition curve for $\mathrm{Au}: \mathrm{Cu}=3$ at $1273 \mathrm{~K}$ compared to COST 531 data

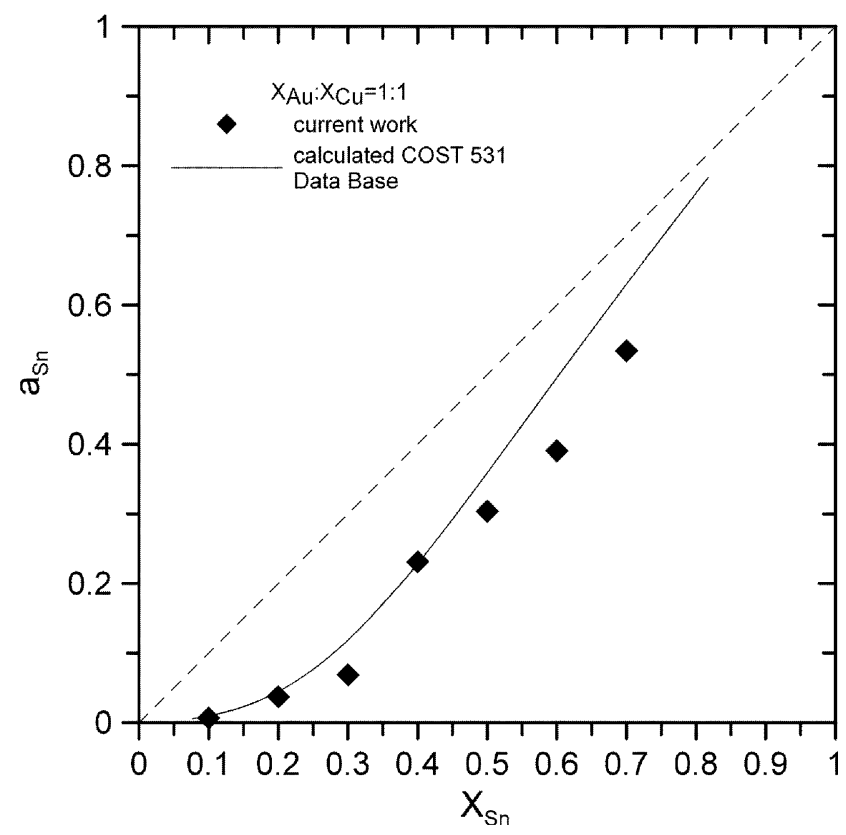

Fig. 4 Tin activity vs. composition curve for $\mathrm{Au}: \mathrm{Cu}=1$ at $1273 \mathrm{~K}$ compared to COST 531 data

\section{Acknowledgments}

This study was performed within the frame of European program "COST Action MP0602-Hisold". The financial support from Polish Ministry of Science and Higher Education under grant No $85 / \mathrm{N}-\mathrm{COST} / 2007 / 0$ has been gratefully acknowledged.

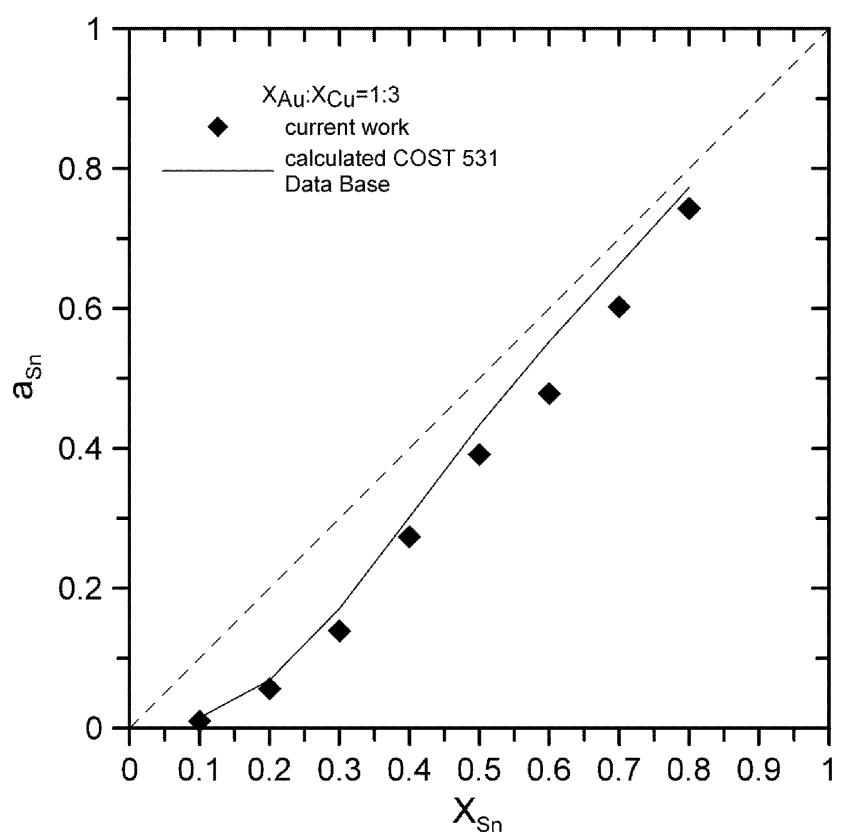

Fig. 5 Tin activity vs. composition curve for $\mathrm{Au}: \mathrm{Cu}=1 / 3$ at $1273 \mathrm{~K}$ compared to COST 531 data

Table 2 Comparison of experimental calorimetric data and $\Delta H$ data calculated from the emf measurements

\begin{tabular}{|c|c|c|c|c|c|c|}
\hline$X_{\mathrm{Au}}$ & $X_{\text {Sn }}$ & $m$ & $\begin{array}{l}-\Delta H_{\exp } \\
\mathbf{J} / \mathrm{mol}^{[1]}\end{array}$ & $\begin{array}{c}-\Delta H_{\text {calc }} \\
\mathbf{J} / \mathrm{mol}\end{array}$ & $\Delta H_{\exp }-\Delta H_{\text {calc }}$ & $\begin{array}{c}\text { Difference, } \\
\%\end{array}$ \\
\hline 0.401 & 0.199 & 1 & 10252 & 9481 & 771 & 8.1 \\
\hline 0.402 & 0.201 & 6 & 8675 & 9499 & -824 & 8.7 \\
\hline 0.332 & 0.334 & 2 & 9648 & 9142 & 506 & 5.5 \\
\hline 0.250 & 0.500 & 3 & 7429 & 7474 & -45 & 0.6 \\
\hline 0.271 & 0.464 & 7 & 7355 & 7973 & -618 & 7.7 \\
\hline 0.184 & 0.545 & 1 & 7878 & 7220 & 658 & 9.1 \\
\hline 0.149 & 0.425 & 2 & 6049 & 6025 & 24 & 0.4 \\
\hline 0.098 & 0.601 & 3 & 3581 & 3747 & -166 & 4.4 \\
\hline 0.238 & 0.684 & 5 & 6758 & 6696 & 62 & 0.9 \\
\hline
\end{tabular}

\section{References}

1. S. Knott, Z. Li, and A. Mikula, Integral Enthalpy of Mixing of Liquid Ternary Au-Cu-Sn System, Thermochim. Acta, 2008, 470, p 12-17

2. G. Garzel and L.A. Zabdyr, Electromotive Force Study of the Liquid Silver-Bismuth-Tin Alloys, J. Phase Equilib. Diffus., 2006, 27(2), p 140-144

3. A. Kroupa, A.T. Dinsdale, A. Watson, J. Vrestal, J. Vizdal, and A. Zemanova, The Development of the COST 531 Lead-Free Solders Thermodynamic Database, JOM, 2007, 59(7), p 20-25 